\title{
Formulation of Generic Simulation Models for Analyzing Construction Claims
}

Rifat N. Rustom (Vce President for IT and External Affairs, Associate Prof. of Civil Eng., Islami University of Gaza, Gaza, Palestine)

\section{ABSTRACT}

While there are several techniques for analyzing the impact of claims on time schedule and productivity, very few are considered adequate and comprehensive to consider risks and uncertainties. A generic approach for claims analysis using simulation is proposed. The formulation of the generic methodology presented in this paper depends on three simulation models; As-Planned Model (APM), As-Built Model (ABM), and What-Would-HaveBeen Model(WWHBM). The proposed generic methodology as presented in this paper provides a good basis as a more elaborate approach to better analyze claims and their impacts on project time and productivity utilizing discrete event simulation. The approach proposed allows for scenario analysis to account for the disputed events and workflow disruptions. The proposed models will assist claimants in presenting their cases effectively and professionally.

Keywords: Construction; Claims; Simulation; Modeling; Time Impact Analysis.

\section{INTRODUCTION}

The construction industry is known for its complex interrelationships and large number of parties involved in it. Due to this nature, work changes would occur and are considered indispensable part of the construction process at

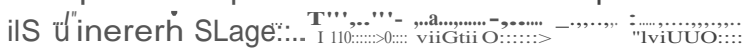
design errors, subsurface conditions, defective material, performance delays, additional work, and a host of other events and conditions. These changes may affect the time, cost and methoof performance of the parties involved in the project and will ultimately affect the project schedule, whether increase the overall project duration or decrease it. Finishing a project on schedule is therefore a difficult task to accomplish in the uncertain, complex, multiparty, and dynamic environment of construction (Kartam, 1999). Because of these changes and the associated impacts, a project will encounter unplanned circumstances that may lead to disputes. Delays, disruptions, and accelerations are considered the most recurring causes of contract problems. Levin (1998) listed the general circumstances that typically cause claims and change orders. Additional work not specified in the contract, strikes, adverse weather, third parties, contractor errors, change orders, and order directed suspensions, are among these causes. In most of the cases, once a dispute has occurred, a claim for financial damage by either the owner or contractor will arise.

Many researchers have addressed delay claims, as the most common type of claims. Alkass et al. (1995) stated that delays on a construction site are normally inevitable and, as a result, many claims arise with few of them ending up in litigation. Assaf et al. (1995) outlined the main causes of delay in large building projects and their relative importance in Saudi Arabia. They found that the most important factors of delay included approvalof shop drawings, delays in contractors' progress payment by owners, design changes, conflicts in work schedules of subcontractors, the slow decision making process of the owner, design errors, and labor shortages and inadequate labor skills. Also, Ogunlana and Promkunton (1996) studied the delays in building projects in Thailand as an example of developing economics. They concluded that the most important problems causing delays are problems of shortages or inadequacies in industry infrastructure,maii11Y supply of resources; problems caused by clients and consultants; and problems caused by incompetence of contractors. Kartam (1999) provided a classification system for de ys on their origin, timing, and compensabrhty.

Among the widely offered methods for analyzing claims due to delays and disruptions are (1) the As-Planned Method; (2) the As-Built Method; 
and (3) the Modified As-Built Method (sometimes called As-Adjusted Method). These methods focused on time impact analysis using time schedules (bar-charts) with deterministic durations. The paper is intended to introduce the general approach to utilize simulation in modeling these methods using probabilistic durations.

\section{STUDY OBJECTIVES}

The time impact analysis tools (bar charts, CPM) used to analyze and prove the basis for delay claims can be detrimental to the acceptance and success of a claim. This paper presents a generic approach for claims analysis using simulation as a promising tool. The models developed provide effective means for analyzing claims at different stages of the project. The approach proposed will assist claimants in presenting their case effectively and other parties, i.e. owners, arbitrators, courts, to comprehend and verify the case.

\section{BASIS OF CLAIMS PROCESS FORMULATION}

Kululanga et al. (2001) laid out the principles (behavior and awareness) that underlay construction claim process which were modeled and developed based on the theory of capturing behavior and awareness in order to measure the effectiveness of an organizational process. They also gave a generic framework that facilitates the management of construction claim process. Kululanga et al. (2001), Easton (1989), European (1996), and Kartam (1999) identified the variables needed in modeling and developing the construction claim process. The variables that are used to model the process are:claim identification, claim notification, claim examination, claim documentation, claim presentation, claim negotiation, and use of total quality management tools to prevent claims.

Claim presentation is one of the main elements that need to be well evaluated and addressed as it provides the ba3is for claim recovery through determining the impact of the claim and calculating the damage.

\section{ANALYSIS OF CLAIMS}

A great deal of time is spent in analyzing documents, producing reports, attending meetings, writing letters, agonizing over negotiations, attending legal hearings, etc. Thus much of the time is spent focusing on processing the claim and not on analyzing the merit and potentiality of the claim (Bramble, 1990). Therefore, evaluating the effect of the dispute (whether delay, acceleration, or disruption) on project time requires not only comparing the asplanned activity dates with the actual performance dates, but a thorough impact analysis of the event on the subsequent activities and future performance measures. McDonald and Baldwin, 1989,illustrated the factors that may delay or disrupt the contractor's performance and the associated effects that may become a basis for a delay or disruption claim. (see Figure 1).

Just as network scheduling has become an important tool in managing a project, it has also become an important evidentiary tool in the presentation and defense of delay and disruption claims in litigation. Courts and boards have held that CriticalPath Method (CPM) schedules are the most effective model for evaluating construction delays (Brennan et. al., 2002). There are various methods covered in construction literature that are considered professionally acceptable for analyzing a schedule impact resulting from project delays and interruptions. Among the widely offered methods are (1) the As-Planned Method;(2) the As-Built Method; and (3) the Modified As-Built Method (sometimes called As-Adjusted Method). Abdulaziz et al. (1998) studied these methods and showed the difference in their applicability on genuine construction schedules. The results of the study indicated that the outcomes of delay analyses are often not predictable, that one method may not be used universally over another in all situations; or one method might prove to be the most desirable from the stand point of the contractor or the owner. Depending on the time and resources available, and the accessibility of project controldocumentation, one method may be more practical or costeffective. 
FACTORS - - - - AND - - - - - EFFECT

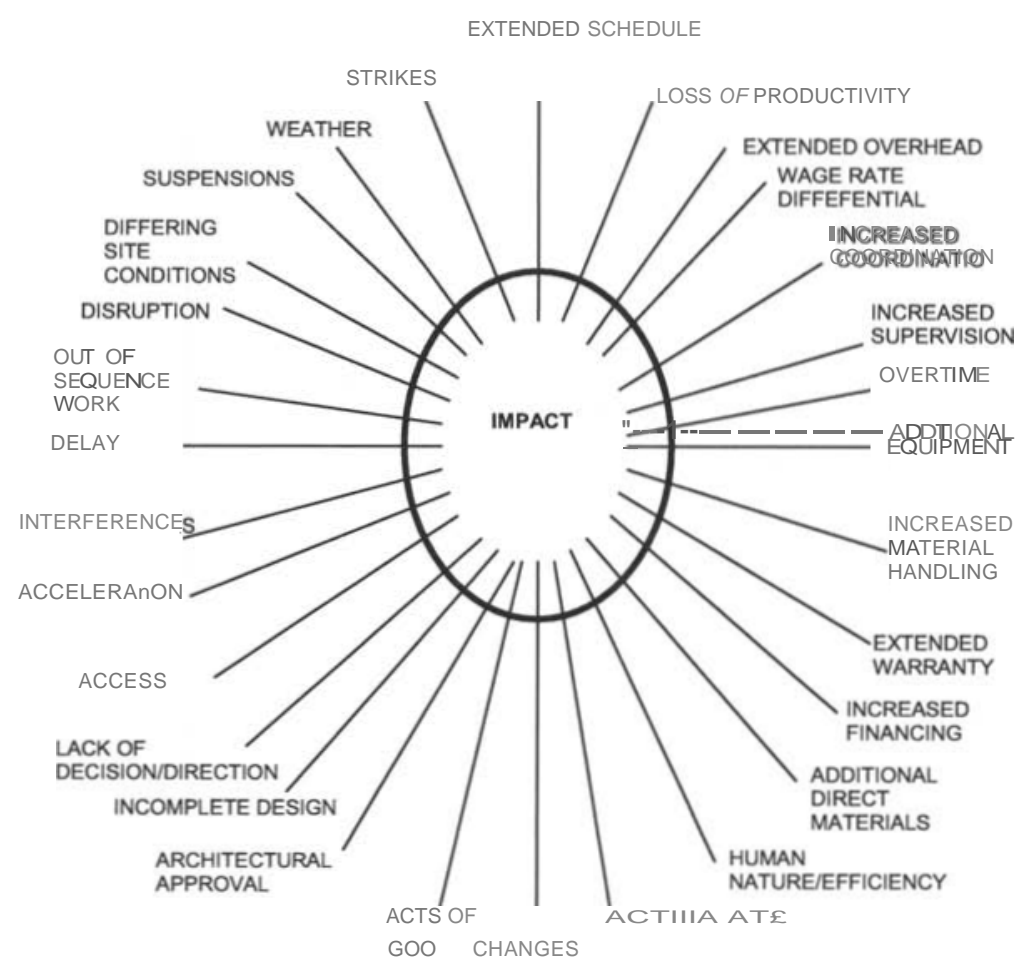

Figure 1: Factors and effects of delays and disruptions (McDonald and Baldwin, 1989).

\section{SIMULATION AS A TOOL FOR ANALYZING CLAIMS}

Few studies were made to utilize the capabilities of discrete event simulation in quantifying time and productivity-related impacts. These studies are demonstrated in the works of Abou Rizk et al. (1993), Vanegas et al. (1993), and Cor (1998). Abou Rizk et al. (1993) simulated two scenarios; first is a model of an operation based on the construction method specified in the contract (As-planned) and the second model simulated the actual operation (As-built). The durations (in terms of man-hr) required to complete the two models were used as a basis to estimate the reasonable range of cost to be awarded to the contractor. Vanegas et al. (1993) indicated that simulation can be used as a preventive tool in the planning stage and as a toolto resolve disputes. They also proposed a framework for use of simulation in claims analysis and dispute resolution. Cor (1998) simulated the As-Planned, As-Built, and AsModified schedules to solve a dispute in an actual case study.
It is clearly seen that most of these studies focused on analyzing specific case studies to demonstrate the robustness of simulation and its capabilities in quantifying productivity related impacts under random conditions.

\section{FORMULATION OF GENERIC SIMULATION METHODOLOGY FOR ANALYZING CLAIMS}

While there are several techniques for analyzing the impact of claims on time schedule and productivity, very few are considered adequate and comprehensive to consider risks and uncertainties. The proposed generic methodology as presented in th:s paper provides a good basis for a more elaborate approach to better analyze claims and their impacts on project time and productivity utilizing discrete event simulation. Based on previous research (Cor, 1998), the features and advantages of process simulation modeling that will be integrated into the generic models are shown in Figure 2. 
- Capability to employ lo cal, decision nodes in the model.

- Capability to involve random and range definitions for all attributes

- Capabihty to experiment with the models under same conditions.

- Convenience in validating the models.

- Capability to involve historical data.

- Convenience for both before and after the fact analysis.

- Convenience to se€1ega.te impacts of each delay in case of multiple delays
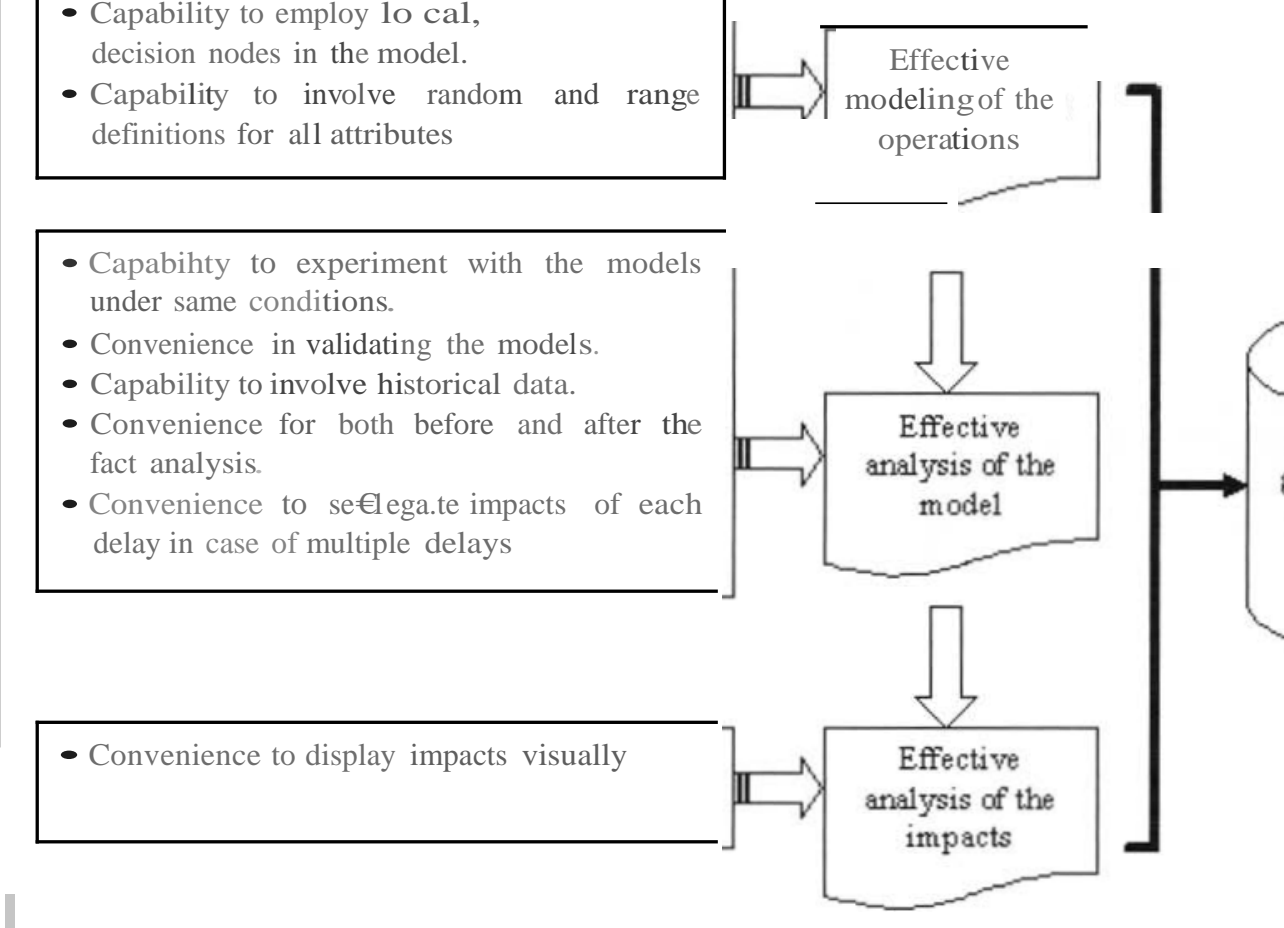

1

Figure 2. Features and advantages of using simulation to Identity claims impacts (Cor, 1998).

The formulation of the generic methodology presented in this paper depends on three simulation models; As-Planned Model (APM), As-Built Model (ABM), and What-Would-HaveBeen Model (WWHBM). Figure 3 outlines the system approach proposed for analyzing claims using simulation. The APM should be the base line for initial evaluation of the status of the project. As most construction projects deviate, to some extent, from ori ginal plans or schedules, actual formulation of the changes upon occurrence should be incorporated in the APM to generate the instantaneous ABM. Upon the occurrence of a problem, $A B M$ is referred to for settling the dispute. Depending on the nature of the dispute and its impact on future activities, two models could be formulated as shown in Figure 3. The AsAdjusted Model (AAM) which will be based on accepted changes and their consequences, thus no claim shall be pursuit, and the other model which will be based on assumptions proposed by the claimant through a series of simulated scenarios (What-Would-Have-Been Model, WWHBM) to show and prove the impact and its consequences on future activities' performance, time, and productivity. As Figure 3 shows, in case of a dispute, the AAM output is used as an input for the WWHBM pending that the changes occurred is not disputed but their consequences or impacts are disputed. The other WWHBM(s) formulated is the AAM including disputed changes. To account for these disputed changes, several scenarios could be generated to support the claim considering the varying effects of the change causes and their consequential damages (delays, disruption, loss of productivity, etc.)

The detailed formulation of the different models discussed above will be presented in the following sections.

\section{FORMULATION OF THE AS-PLANNED MODEL (APM)}

The As-planned model (see Figure 4) is a simulation model built to show how the basic understanding of the contractor affects his choice of means and methods (Haldun, 1998). The (APM) is built during the bidding phase. or planning phase. to represent the expected behavior of the project and before the actual start of the project. As Figure 4 shows. the simulation model should incorporate all processes leading to the successful completion of the project along with their logical interconnection. Each process is also 
decomposed into activities with specific time functions, resources assignments and cost data. The input data used is the data available at bidding time or project inception phase and could include activities sequencing and their logical relationships (work plan), estimated activities durations, estimated resources production rates, and expected methods that would be followed to execute the work in the field. The estimated activities duration and production rates would generally be in probabilistic form to reflect the uncertainty and risk in estimation. Historical data of past records could be used to generate probability distribution functions (beta distribution could be used as most frequently used in construction, Maio, et al., (2000)). If these records are not available, triangular distribution functions could be used, where the user should only specify three values, maximum, minimum and most likely. The output expected from the simulated model would include minimum, average, and maximum values of assigned activities durations, total project duration and resources utilization. The output of the APM will be considered as the baseline or reference for other models upon starting the project.

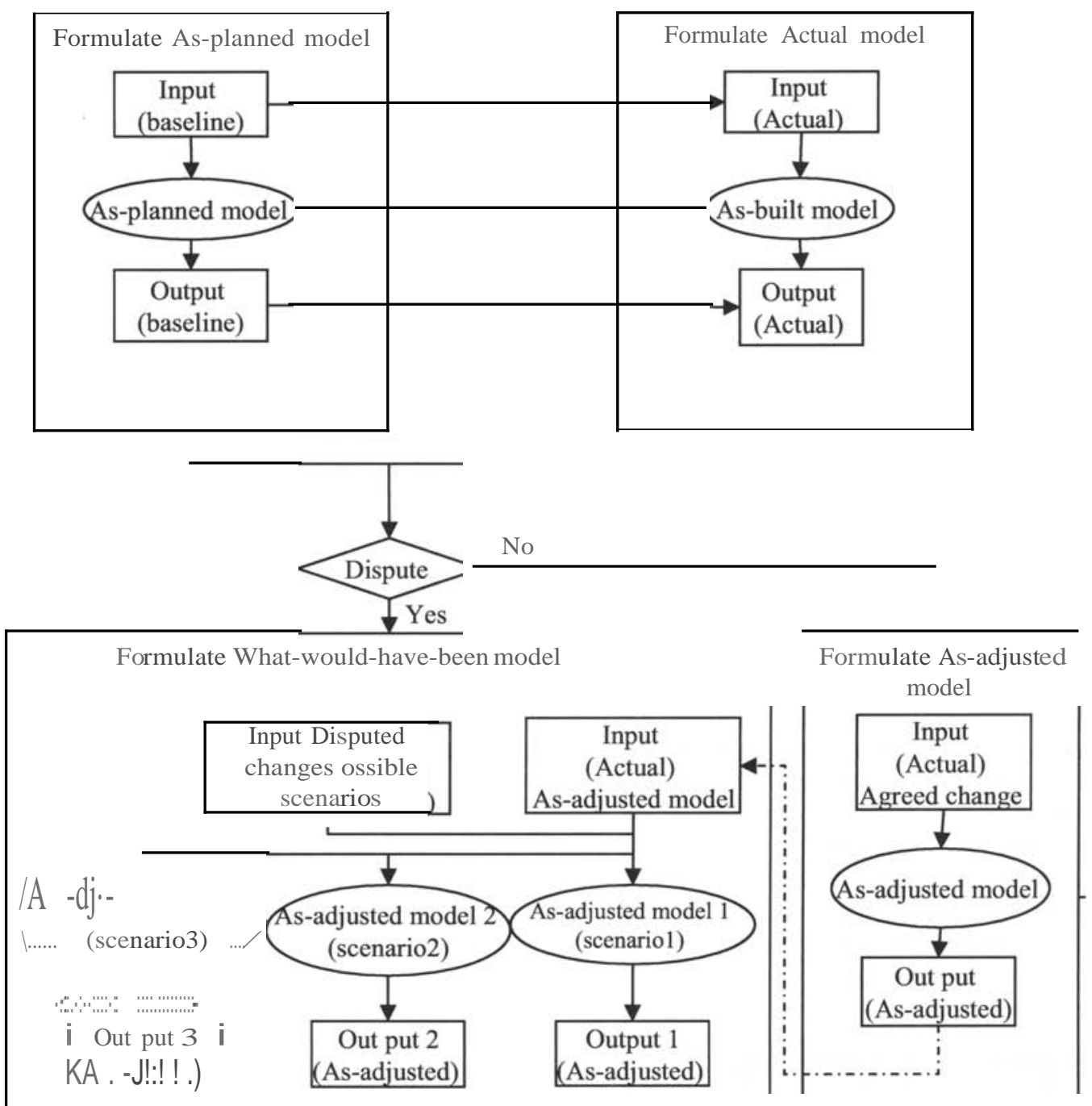

Figure 3: System approach proposed for analyzing claims using simulation 


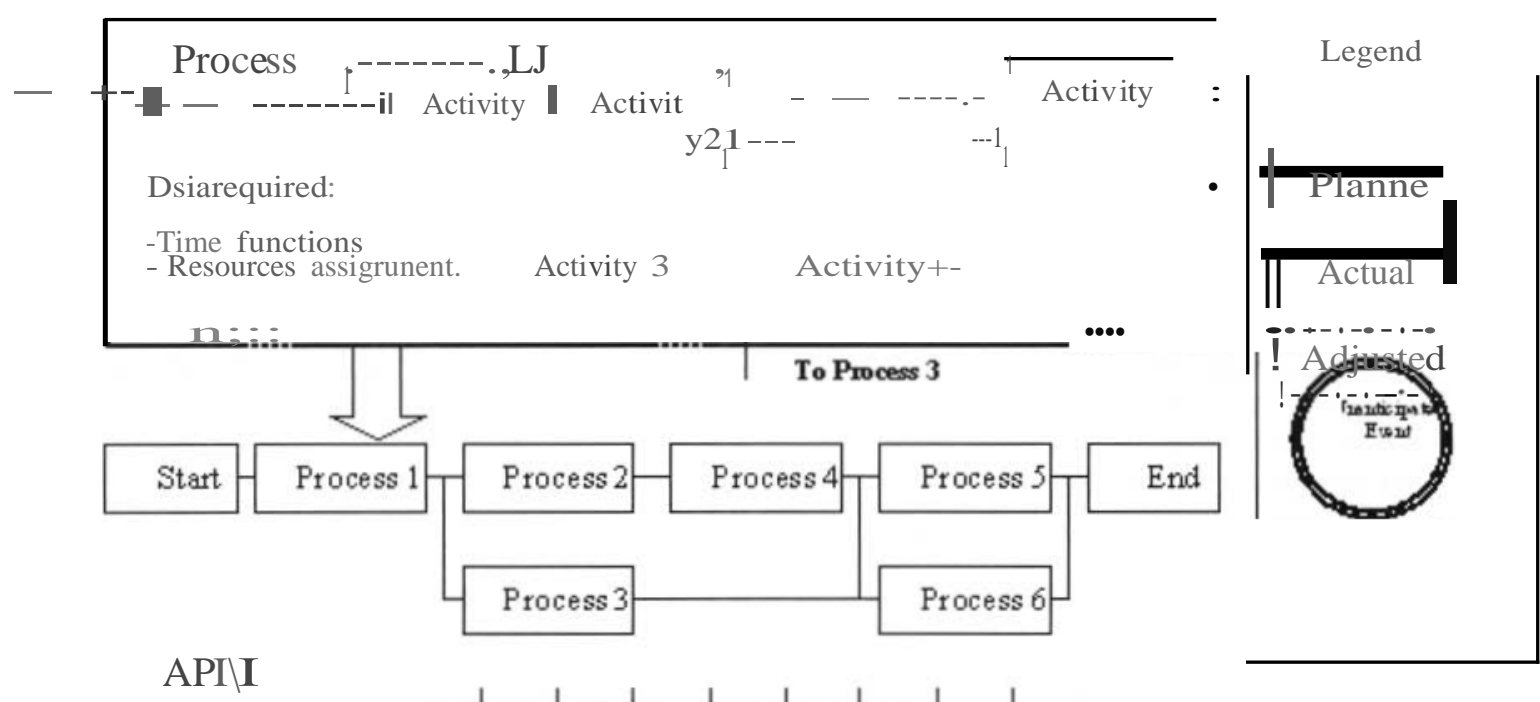

Time

Figure 4: Formulation of the As-planned model

FORMULATION OF THE AS-BUILT MODEL (ABM) AND AS-ADJUSTED MODEL (AAM)

The As-built model (ABM) is built after the start of the project or during the implementation phase. The APM, reference model, is to be modified based on actual performance up to the status or evaluation date. As Figure 5 shows, the simulation model should incorporate actual processes up to the event of delay and those planned or rescheduled processes (i.e. process 2 becomes process 2-

1 to account for the event before the delay and process 2-2 to include the impact of the delay). As illustrated in the formation of the APM, each process is also decomposed into activities with specific time functions, resources assignments and cost data. The input data used in this model is the actual data and could include actual activities sequencing and their logical relationships and consequences with other future planned activities, actual activities durations, actual resources production rates, and actual processes or methods used to execute the work in the field. The actual activities durations and production rates could be used to generate probability distribution functions that could be used, at a later stage, to either modify similar planned activities or account for delays or interruptions. Any agreed upon changes or variations should be incorporated into the $A B M$ to generate the As-Adjusted Model (AAM). The $A A M$ will then become the new reference model, ABM, for future updates or changes. Figure 5 illustrates the ABM.

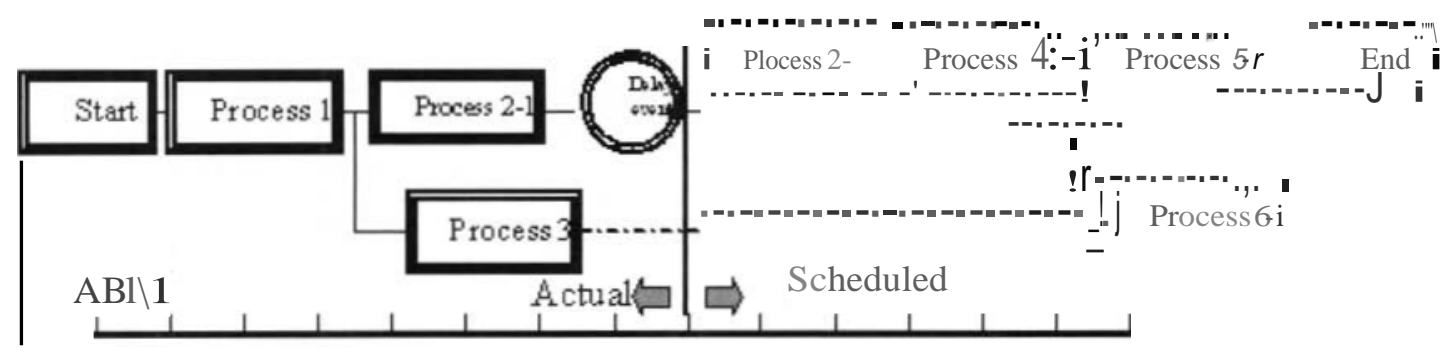

Time 
FORMULATION OF THE WHAT-WOULDHAVE-BEEN MODEL (WWHBM)

The goal of this model is to identify the disputed event, the impact of this event, and the plan to complete the remaining work at the time the event occurred. As shown in Figure 6, to formulate this model, first, the status of the model must be established at the time those events occurred (reference is made to the updated ABM or the AAM (see Figure 3)). Second, the model is to be updated to incorporate the direct events (delay, disruption, acceleration, etc.) Third, the model is to be reconfigured to allow for different consequentional impacts through incorporating any planning changes to coincide with the claimant's plan for pursuing the work, thus allowing for scenario analysis or what-if analysis. A what-if scenario allows the claimant to see the impact of the event on the overall project duration as well as at any specific point in time through using record modules. Figure 6 illustrates the WWHBM. The flexibility in building the model and incorporating changes allow for the most commonly used approaches in time analyses (as an output); namely, Time Impact Analysis and Window Analysis (Contemporaneous Method). Time Impact Analysis looks at a particular point in time and utilizes a series of chronological time slices to evaluate major scheduling variations that occurred during the project; while Window Analysis examines the critical path flow between two points in time and assesses the delay as it occurs. This contemporaneous method is favored because it provides a baseline for measuring the delay or other disruption event; the status of the project at the time a delay occurs; the impact of delaying events on remaining work; changes to the path flow, and revisions to the plan to complete (Brennan and D'Onofrio, 2002).

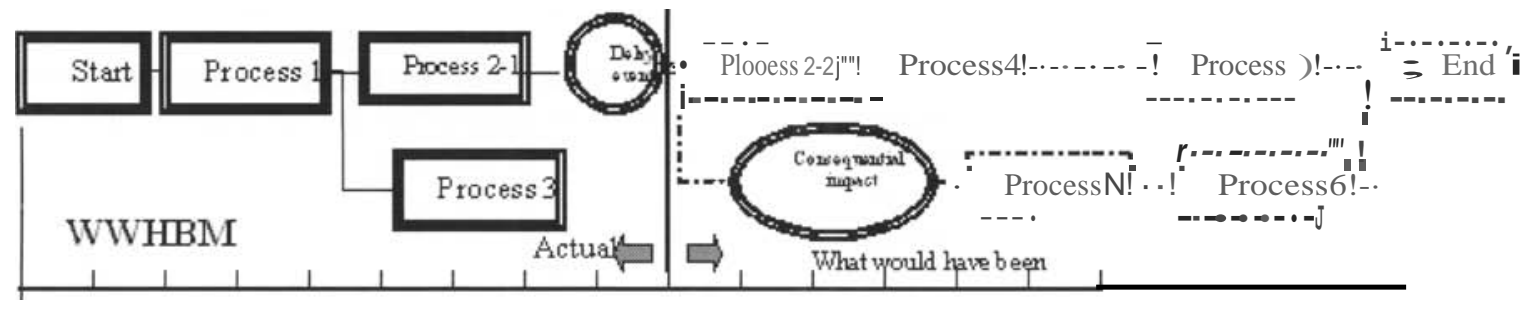

Time

Figure 6: Formulation of the What-Would-Have-Been model

The utilization of the Record modules in simulation software (i.e. ARENA, 2005) allows easily for tracking these time changes at specific points in the model, thus enabling for the comparison between the ABM and WWHBM.

The input data used in this model is the actual

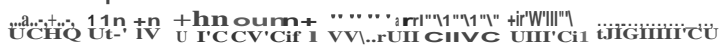
data for the scheduled unchanged activities, and impacts data (anticipated and consequential). The impact data could include new activities (or events) durations, impacted resources production rates (considering effectiveness and efficiency), new performance methods to execute the work, changes in activities sequencing, etc.
The simulated model will allow for the determination of several useful data that favorably support the claimant. The output expected from the simulated WWHBM models (based on various proposed scenarios) would include among other things minimum, average, and maximum values of the impacted activities durations, total project duration, and resources

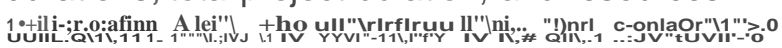
impacts will be identified.

\section{ADVANTAGES OF SIMULATION COMPARED TO CPM SCHEDULING TECHNIQUE}

Although CPM has gained wide reputation in claims analysis, nevertheless, claim analysis by using the proposed ABM and WWHBM 
simulation models can be a promising tool due to the following:

- The simulation models do not necessarily require the identification of the critical path or floats to see the effect of delay on the project duration.

- The simulation models allow flexibility in modifying the model and run scenario analysis to see the impacts by just adding events (or sub models) at any part of the model to reflect the expected impact.

- The simulation models can allow isolating part of the model through the formation of sub models to study local or specific impacts on certain processes or other sub models.

- The processes in these simulation models can be assigned priorities, thus allowing for critical path flow identification at both planning and implementation stages.

- Project resources can also be assigned priorities, thus allowing for tracking utilization properly at different time frames wwhether in the planning or implementation phase).

These simulation models can be integrated with CPM scheduling, whether through analyzing specific work segments or time frames or for optimizing the possible scenarios based on available and impacted resources utilization.

\section{CONCLUSION}

To allow for analyzing the impact of claims on time schedule and productivity considering risks and uncertainties, a generic approach for claims analysis using simulation is proposed. Three simulation models; As-Planned Model (APM), As-Built Model (ABM), and What-Would-HaveBeen Model (WWHBM) were developed. The As-Planned Model (APM) serves as a base line for initial evaluation of the status of the project thus allowing for documenting the status of the project before commencing the work. The (ABM) is built after the start of the project or during the implementation phase. Based on acceptance of the dispute event, two models can be generated; the As-Adjusted Model (AAM) which will be based on accepted changes and their consequences; and the other model which will be based on assumptions proposed by the claimant through a series of simulated scenarios (What-Would-Have-Been Model, WWHBM) to show and prove the impact and its consequences on future activities' performance, time, and productivity.

\section{ACKNOWLEDGMENT}

The author would like to thank his graduate student Mr. Omar El Tabba for his assistance in preparing parts of this manuscript.

\section{REFERENCES}

AbouRizk, Simaan, M. \& Dozzi, P. (1993). Application of computer simulation in resolving construction disputes, J. Constr. Engrg. and Mgmt., ASCE, 119(2).

Alkass, S., Mazerolle, M., Tribaldos, E., \& Harris, F. (1995). Computer aided construction delay analysis and claims preparation. Constr. Mgmt. and Economics, 13(4), 335-352.

ARENA, (2005). Rockwell Automation, Inc. URL http://www .arenasimulation.com/

Assaf, S. A., Alkhalil, M., \& Al-Hazmi M. (1995). Causes of delay in large building construction projects. J. of Mgmt. in Engrg., ASCE, 11\{2), 4550.

Bramble, B. B., D'Onofrio, M.F. \& Stetson, J. B. (1990). Avoiding and resolving construction claims. R.S. Means Company, Inc.

Brennan, F. \& D'Onofrio, M. (2002). News from $\mathrm{CPMI}$ on construction claims analysis and resolution. Cause \& Effect. Issue 1, spring. Capital Project Management, Inc.

Bubshait, A. and Cunningham, M. (1998). Comparison of delay analysis methodologies, $J$. Constr. Engrg. and Mgmt., ASCE, 124(4), 315322.

Cor, H. (1998\}. Using simulation to quantify the impacts of changes in construction work. Thesis submitted to the Faculty of the Virginia Polytechnic Institute. Virginia, USA.

Easton, G. R. (1989). Construction claims. Dept. of Civ. Engrg., Loughborough University, U.K.

European Construction Institute. (1996). Implementing total quality in construction industry. Thomas Telford, London. 
Kartam, S. (1999). Generic methodology for analyzing delay claims. J. Constr. Engrg. and Mgmt., ASCE, 125(6), 409-419.

Kululanga, G. K., Kuotcha,W., McCaffer, R., \& Edum-Fotwe, F. (2001). Construction contractors' claim process framework. J. Constr. Engrg. and Mgmt., ASCE, 127(4), 309-314.

Levin, P. (1998). Construction contract claims, changes, and dispute resolution. 2"d edition. ASCE Press.

McDonald, P. R. \& Baldwin, G. C. (1989\}. Builder's and contractors handbook of construction claims. Prentice-Hall, Inc., Englewood Cliffs, NJ.

Maio, C., Schexnayder, C., Knutson, K., \& Weber, S. (2000). Probability distribution functions for construction simulation. J. Constr. Engrg. and Mgmt., ASCE, 126(4), 285-292.

Ogunlana, S.O. \& Promkunton, K. (1996).

Construction delays in a fast-growing economy: comparing Thailand with other economies. Int. J. of Proj. Mgmt., 14(1), 37-45.

Vanegas, Jorge A. \& Halpin, Daniel W. (1993). Use of Construction Simulation in Claims Analysis, Proceedings of the Fifth International Conference Computing in Civil and Building Engineering, Anaheim, California, June. 